\title{
Reply to Martin Tanner and Colleagues
}

To the Editor:

In reply to the Letter to the Editor from Martin Tanner and his colleagues, I must stress the following points. First, it is amusing that the authors appeal to Webster's II New College Dictionary (1995) to talk about science. I am certain that the people best entitled to talk about science, its structure, philosophy, and methodologies, are the ones working on it. I invite Tanner and his colleagues to inspect some of our publications (Gómez-Jeria, Ojeda-Vergara, and DonosoEspinoza, 1996; Morales-Lagos and Gómez-Jeria, 1991) to appreciate that scientific research is something very serious.

Second, we were not disguising any "particular agenda" such as monism with pronouncements of scientific objectivity. Our rejection of dualism was based not on the state space concept, which is only a formalism, but on evolutionary arguments derived from various scientific disciplines (Gómez-Jeria and Madrid-Aliste, 1996). If Tanner and his colleagues believe in the existence of a soul or "essence," I invite them to state in the Journal their ideas about when and how this supposed soul appeared in the evolution of humankind: did it appear in Homo habilis, or maybe in Australopithecus afarensis, or 
perhaps only in Homo sapiens sapiens? Unless they are followers of some obscurantist line of thinking, like creationists, or invoke the well-known argument "... then a miracle occurs," I am sure they will have to work hard to answer this question.

Third, it would be easy for us to dismiss near-death experiences (NDEs) or out-of-body experiences (OBEs) as reports of silly and/or sick people. We did not do that. We chose to accept the evidence as representing something that science must and will explain. Actually, the scientific modeling of the NDE has already been accomplished (Gómez-Jeria and Saavedra-Aguilar, 1994; Saavedra-Aguilar and Gómez-Jeria, 1989), and it is only a matter of time before better and more complete models are proposed. We are actually working on a model to explain the OBE without invoking souls or "essences." But please do not make a potpourri of the experience itself, its report, and its interpretation!

Fourth, there is nothing wrong with a paradigm shift if there are data making the previous paradigm obsolete. The problem here is that there are no such data. For example, the fact that unconscious people are able to perceive the external world was tentatively explained some time ago (Gómez-Jeria and Saavedra-Aguilar, 1994), as was the contamination of the experience by cultural influences (Gómez-Jeria, 1993). Alluding to the Newton/Einstein paradigm shift to support their claims only shows the weakness of their arguments.

Fifth, I invite Tanner and his colleagues to analyze and discuss deeply some questions like the following:

(a) How do people recognize spirit beings? For example, do they have wings or carry labels? By analyzing the reports of alleged "spiritual beings" it seems to me that they are like the terrifying extraterrestrials always visiting our poor Earth: of all sizes, shapes, colors, and so on.

(b) How can it be asserted that this alleged "spiritual body" has an immensely improved knowledge, which often is removed from the memory upon "return"? We normally expect that, by definition, something removed from the memory cannot be remembered!

(c) Some people claim that the out-of-body body is a form of energy; what kind of energy could that be? electromagnetic? nuclear? gravitational? or something so subtle and special that it cannot be measured or studied?

(d) How does this alleged out-of-body body interact with the physical body? It would be helpful if Tanner and his colleagues could propose a model based, for example, on the suggestions of John Eccles 
(1994). This might foster a serious discussion, despite the fact that Eccles' work is an amusing but scientifically poor defense of dualism.

(e) This alleged out-of-body body continues to exhibit all the independent consciousness traits and ego of the living physical body. Let us consider vision as an example. The first step in vision is the arrival on the retina of energy of certain wavelengths and intensities; the retina does not receive a photograph of the external world! After a complicated process that science is beginning to elucidate, a representation of the external world is created. Does the out-of-body body have a retina? If not, how can it see?

I shall not comment further on pseudoscience, NDEs, and OBEs at this time, because we are preparing a longer work on this topic. In conclusion, Tanner and his colleagues failed to present anything vaguely similar to a model to sustain dualism. Their proposition crashes against all the available scientific data coming from several disciplines and their ideas cannot even be tested experimentally. Therefore, all their efforts remain in the realm of wishes and beliefs.

\section{References}

Eccles, J. H. (1994). How the self controls its brain. New York, NY: Springer-Verlag. Gomez-Jeria, J. S. (1993). A near-death experience among the Mapuche people. Journal of Near-Death Studies, 11, 219-222.

Gómez-Jeria, J. S., and Madrid-Aliste, C. (1996). Evolution and the relationship between brain and mind states. Journal of Near-Death Studies, 14, 251-272.

Gómez-Jeria, J. S., Ojeda-Vergara, M., and Donoso-Espinoza, C. (1996). Quantumchemical structure activity relationships in carbamate insecticides. Molecular Engineering, 5, 391-401.

Gómez-Jeria, J. S., and Saavedra-Aguilar, J. C. (1994). A neurobiological model for near-death experiences. II: The problem of recall of real events. Journal of NearDeath Studies, 13, 81-89.

Morales-Lagos, D., and Gómez-Jeria, J. S. (1991). New developments in the continuum representation of solvent effects. Journal of Physical Chemistry, 95, 5308-5314.

Saavedra-Aguilar, J. C., and Gómez-Jeria, J. S. (1989). A neurobiological model for near-death experiences. Journal of Near-Death Studies, 7, 205-222.

Websters's II new college dictionary. (1995). Boston, MA: Houghton-Mifflin.

Juan S. Gómez-Jeria Associate Professor Universidad de Chile Facultad de Ciencias Casilla 653, Santiago

Chile 